among the experts there appears to be some misuse of tests of gastric function. For instance, though there would seem to be no clinical rationale for performing acid tests on patients with dyspepsia who have not had a gastroscopy or barium meal, $14 \%$ of the gastroenterologists did so. A much higher proportion $(80 \%)$ did acid tests on patients with a convincing history of peptic ulcer but who had a normal barium meal. This is reasonable, for in a third to half of patients with a duodenal ulcer secretion of acid is above the normal range, and it is thus possible to diagnose duodenal ulceration in the absence of $x$-ray changes. This is of particular importance if the patient's symptoms are sufficiently severe to warrant consideration of surgical operation.

Two-thirds of British gastroenterologists measured the secretion of gastric acid in patients with gastric ulcers. This is surprising, for, in Baron and Williams's view, the results of tests of acid secretion do not indicate the clinical course or whether or not surgical treatment is required. The only clinical information of value to come from acid tests for gastric ulcer is if complete achlorhydria is found. This would indicate that the ulcer is a carcinoma. However, as complete achlorhydria is found in only one in five patients with carcinomatous ulcer, ${ }^{5}$ the chance of making the correct diagnosis by this means is too small to justify the time, labour, and discomfort to the patient. It is now relatively simple to obtain gastric biopsy specimens under direct vision by using a fibrescope with biopsy attachment. This would seem to be a better investigation for gastric ulcers.

In the rare condition of intractable peptic ulceration due to hypersecretion of gastrin-the Zollinger-Ellison syndrometests of gastric acid are helpful. In the typical case the basal acid output is high and is little increased by stimulation. In some cases the results of acid tests are not clear-cut, ${ }^{6}$ and it seems likely that estimation of gastrin activity in the blood will ultimately replace tests of gastric function for this condition.

Are tests of gastric acid necessary to decide whether or not a patient with a duodenal ulcer needs surgical treatment? In Baron and Williams's opinion the answer is No. However, half to two-thirds of British gastroenterologists were influenced in deciding about surgery, at least sometimes, by acid secretion values. Despite the apparent practice of many gastroenterologists, probably most physicians and surgeons in Britain would agree with the view that the decision whether to operate should be taken on clinical criteria alone.

Tests of gastric function are informative to the surgeon if the patient develops symptoms after gastric surgery. In patients who have had a vagotomy an insulin test is useful in deciding whether or not the vagotomy is complete. There is also evidence that gastric acid tests give helpful information about patients with dyspepsia after partial gastrectomy, and three-quarters of the gastroenterological surgeons, but surprisingly only one-quarter of the gastroenterological physicians, used them in this situation. There seems to be no necessity to do tests of gastric function in asymptomatic patients after partial gastrectomy. After vagotomy an insulin test assesses the skill of the surgeon and gives an indication of the prognosis.

It should be stressed that gastric acid tests are of value only if done carefully by an experienced team. For peptic ulceration they are clinically indicated in three circumstances: $x$-raynegative dyspepsia, or when the diagnosis of duodenal ulceration is in doubt; recurrent dyspepsia after partial gastrectomy or vagotomy; and if a diagnosis of ZollingerEllison syndrome is being considered. It would appear that tests of gastric acid secretion are being misused even by gastroenterologists.

1 Schwartz, K., Beiträge zur klinischen Chirurgie, 1910, 67, 96.

Croft, D. N., Pollock, D. J., and Coghill, N. F., Gut, 1966, 7, 333.

Baron, J. H., Scandinavian fournal of Gastroenterology, Supplement, 1970, 5, No. 6, p. 9.

- Kay, A. W., British Medical fournal, 1953, 2, 77.

- Fischermann, K., and Koster, K. H., Gut, 1962, 3, 211.

- Winship, D. H., and Ellison, E. H., Lancet, 1967, 1, 1128.

\section{Termination of Life}

So confused have the arguments for and against euthanasia often been that the B.M.A. report ${ }^{1}$ issued this week is wise to start with some definitions. Brought into use in the seventeenth century, according to the Oxford English Dictionary, the word means simply "a quiet and easy death." Later it was extended to include the means of procuring it or the action of inducing it. In its present sense it means the deliberate termination of life of a person suffering from a distressing and irremediable disease. Thus from denoting an aspiration that every doctor would wish for his patient, an easy passage from this life, the term has come to mean something that is wholly contrary to the ethics and traditions of medicine-namely, the deliberate causing of a person's death, in fact the killing of his patient if it is a doctor who carries out this act.

The last Bill ${ }^{2}$ to come before Parliament achieved a second reading in the House of Lords in 1969, when it was defeated by 61 votes to 40 . That it attracted so many supporters as that is a matter for some surprise, for it enabled both physicians and nurses to end their patients' lives under certain conditions. One of these was that the patient must make a written declaration requesting euthanasia "If I should at any time suffer from a serious physical illness or impairment reasonably thought in my case to be incurable and expected to cause me severe distress or render me incapable of rational existence." If the patient became incapable of giving directions, euthanasia was to be carried out at the discretion of the physician in charge of the patient.

Some declaration of this kind must be at the centre of any legislation enabling euthanasia to be carried out. Yet it is hard to see how it can possibly safeguard the patient's true interests. His mental state when committing himself so firmly to the possibility of his own extinction must be difficult for his doctor to ascertain, to say the least. Certainly there are robust rationalists who can weigh up the meaning of alternative possibilities in a calm and collected way, and who can contemplate having a preference for death in certain circumstances. But the experience of many doctors is that such people are remarkably few and that the full resources of medicine will allow a peaceful end to almost all the patients who need them. Moreover, the will to live when directly challenged is apt to be found much stronger than it is often credited with being in rational discussion. Even so, the existence of legal euthanasia might tragically undermine the patient's endurance by making him feel some obligation-even if not reminded of it by a hint from an impatient relative-to sign away his life.

The suicide of a patient when he is under medical care may be more of a reproach for the inadequate treatment he has received than a consequence of any clear assessment of his real prospects. So too a decision to ask for euthanasia might commonly be based on serious misunderstandings. In fact the whole movement itself is open to the same suspicion. Do those who advocate euthanasia and vote for it really understand 
what oppression they could put on the confused, sensitive, and perhaps weakened minds of apprehensive or actually suffering patients? In this context the argument that they are conferring the freedom to die takes on a less appealing aspect than it purports to wear in offering people a civil liberty they do not at present possess.

In the last resort the legalization of euthanasia is, as Lord Brock has said, ${ }^{3}$ a social rather than a medical problem, and doubtless more will be heard of it from its advocates. The vast majority of doctors will agree with the view Sir George Pickering expresses in the address published at page 191 of the B.M.f. this week: "I reject euthanasia-killing people is not what doctors should, or could, do." He goes on to speak then of the problem that increasingly often confronts the medical profession nowadays of the old patient with bronchopneumonia, and his advice in effect is to let nature take its course rather than to try to preserve in a distressing condition a life already running down. But the profession would be wise to do more than simply declare the practice of euthanasia to be unethical, repugnant, and destructive of the trust that people repose in their doctors. For it is important that lay people themselves should understand the burden such legislation could impose on them as patients, especially in circumstances when their ability to bear it might be feeble. With their unique, objective experience of how their patients live and die, doctors have an obligation to advise them on that.

\footnotetext{
1 Special Panel of the Board of Science and Education of the British Medical Association, The Problem of Euthanasia. London, British Medical Association, 1971 (3s. or 15 new pence net).

2 Voluntary Euthanasia Bill (H.L.), 1969

3 British Medical fournal, 1969, 4, 229.
}

\section{Cutting Down on Barbiturates}

The voluntary ban by family doctors on the prescribing of amphetamines, pioneered at Ipswich, ${ }^{1}$ has now spread to other parts of Britain. Since experience with this group of drugs has shown that the indications for prescribing them are rare, ${ }^{2}$ a voluntary agreement among general practitioners to provide alternative treatment is not difficult to arrange given good will and understanding. The commendable result is that abuse of the drug has been made extremely difficulteven perhaps eradicated-in the areas where the ban operates. $^{3}$ If general practitioners throughout the country are persuaded to see whether they can follow the Ipswich lead, nothing but good will result.

Now enthusiasts are turning their attention to other drugs that may be subject to abuse, and not surprisingly the barbiturates are being cited as a group that could be prescribed much less than they are. The number of prescriptions for them in the United Kingdom under the National Health Service in 1968 was reported to be $24,700,000 .{ }^{4}$ Of these some 16 million were considered to have been prescribed principally as a hypnotic, and they were in addition to over 5 million prescriptions for non-barbiturate hypnotics. That sleep does not come easily to under-exercised and over excited urban populations may be granted, but can these millions of hypnotic tablets really be needed? Undoubtedly some of them lie in bathroom cupboards, a menace to exploratory children, experimenting teenagers, and depressed adults. The wisdom of never treating the prescribing of hypnotic drugs as a routine affair has often been urged, and doctors who examine their patients' needs critically usually find that some reduction in the number of tablets prescribed is possible and even beneficial.

Though barbiturates, like the amphetamines, have lately become attractive to people who take drugs illicitly, they do not in therapeutic doses medically prescribed carry the serious risks of mental disturbance that the amphetamines do, nor are unpleasant side effects common. Again in contrast to the amphetamines, which have so few genuine indications, they are fairly effective palliatives of a common condition, insomnia. Consequently before the question of banning them or even cutting down the prescribing of them at all drastically is considered the possibility of providing a satisfactory alternative hypnotic must be assured. Perhaps some insomniacs would do better to read the right kind of book, drink a comforting "nightcap," or switch off the television an hour earlier, but for others the merciful oblivion of sleep may be elusive without medicinal aid. Whether any of the more recently introduced hypnotic drugs are both as efficacious and as safe in proper dosage as the well-tried barbiturates must be regarded as still debatable. But some do seem to have the undoubted advantage of being safer in gross overdosage. Since one of the common causes of urgent admission to hospital at present is self-poisoning with a barbiturate, any measure to make this group of drugs less readily available must be welcomed on that score alone, though there is a risk that a dearth of barbiturates might simply turn the attention of self-poisoners and attempted suicides to other drugs.

The success of the amphetamine ban may have to be seen not so much as an example to be precisely followed in the prescribing of barbiturates as a stimulus to look at the best way of prescribing-or not prescribing-the hypnotic drugs by reference to their own properties and uses.

\footnotetext{
1 Wells, F. O., British Medical fournal, 1970, 2, 361.

Working Party of the B.M.A. Committee on Medical Science, Education and Research, British Medical fournal, 1968, 4, 572

Wells, F. O., British Medical fournal, 1970, 4, 552.

Dunlop, Sir D., Proceedings of the Royal Society of Medicine, 1970, 63, 1279 .
}

\section{Epidemiologists on the March}

The great epidemics of the past such as plague, smallpox, enteric fever, and cholera were commonly recognized to be in some sense communicable even when they were believed to have a spiritual cause. During the nineteenth century, therefore, the discovery that transmissible micro-organisms were responsible for many of the prevalent distempers of the time attracted medical and some celebrated lay people as well to the study of the crowd diseases. The first epidemiologists laid the foundations of this branch of science as one of the main supports of the sanitary reforms that the growth of cities made so necessary. But the men studying the crowd diseases devised methods that were found to have a wider application, while at the same time we have seen in the twentieth century the conquest of infections to a remarkable extent in the developed countries. The methods that the epidemiologists had invented for the study of one kind of disease in populations rather than individuals were now to 